Celal Bayar University Journal of Science

\title{
CFD Modelling of Non-Newtonian Fluid Flow in a Pipe Including Obstacle
}

\author{
Mustafa Murat YAVUZ ${ }^{1}$ (iD), Pınar SARI CAVDAR ${ }^{2 *}$ (iD) \\ ${ }^{1}$ İzmir Democracy University, Department of Mechanical Engineering, 35140 İzmir, Turkey \\ ${ }^{2}$ İzmir Democracy University, Department of Civil Engineering, 35140 İzmir, Turkey \\ * pinar.cavdar@idu.edu.tr \\ $* 0000-0002-1989-4759$
}

Received: 20 January 2021

Accepted: 5 April 2021

DOI: $10.18466 /$ cbayarfbe. 865261

\begin{abstract}
Pipe flow problems are important in transportation of wastewater, oil lines and supply of water. In this study, a non-Newtonian fluid model is discussed and a CFD solution is presented for flow geometry. The effects on velocity, pressure, dynamic viscosity and cell Reynolds number are discussed for different parameters of flow inside the pipe. Power Law function is considered in the analyses. The velocity profile increased and get more parabolic distribution when flow behaviour index, $\mathrm{n}$ was increased. That supports lower pressure profile in the pipe flow. The lowest $\mathrm{n}$ value causes to increase the sensitivity for viscous effects. The increased flow consistency index, $\mathrm{K}$ causes to increase dynamic viscosity but decreases the Re number. Results are given in different graphs and contours.
\end{abstract}

Keywords: non-Newtonian fluid, power law, CFD.

\section{Introduction}

Fluid flow in pipes is used in many areas of mechanical and civil engineering. Heating and cooling applications and fluid distribution networks can be cited as common usage areas for liquid and gas flow. Many fluids, especially liquids, are transported by circular pipes. The reason why circular pipes are used is that they can withstand large pressure differences between inside and outside without deterioration.

Several researchers have analysed the problems of boundary layer flow of non-Newtonian fluids past different geometries in the past. [1-6].

Power-Law fluid model has been carried out by many scientists [7-13]. Gupta [14] carried out a new approximate solution for laminar flux of power-law fluid. Flow model is considered for pipe and straight channels. The results of different methods for pipe and channel flow are compared according to parameters such as pressure, velocity, and length of the boundary layer. Alexandrou et al. [15] have examined the steady state of the non-Newtonian fluid in the HerschhelBulkley model by considering the expansion of the canal in three dimensions at different rates.
Cebeci et al.[16] and Acrivos et al. [17] have compared laminar boundary layer of non-Newtonian fluid made by approximate solution of the equations by asymptotic method with numerical solution of the equations of power law flux.

Hornbeck [18] worked laminar flow of a compressible fluid in the inlet of a pipe numerically and his numerical technique allows a closer approximation to the basic equations of fluid motion than has been possible in previous investigations. Yapıc1 and Albayrak [19] studied the temperature distributions inside the pipe wall and fluid for uniform and non-uniform heat fluxes. Two different mean flow velocities are considered, and the stress distribution is presented inside the pipe wall.

Yildırım et al. [20] examined the wave motion at the interface of two fluids and investigated wavelength, wave number, frequency, amplitude, wave and growth rate in $2 \mathrm{D}$ numerical analysis, taking into account the Kelvin-Helmholtz (KH) type instability.

Kırmızıgöl et al. [21] studied both steady-state and time-dependent (transient) computational fluid dynamics (CFD) analysis of the cooling channels and the die cooling system, both in conjugate and solid-only models, performed and compared the pipe flow part of the results with the available experimental data. 
Sorgun et al. [22] analysed pipe roughness influences on frictional pressure losses of water with CFD. Batool and Nawaz [23] investigated thermal enhancement of nonNewtonian fluid in micropolar fluid structures. The increased viscosity parameter shifted great vortices to the top wall. Mehryan et al. [24] studied melting process of a non-Newtonian fluid inside a metal foam and determined the effect of power-law index on melting process. Jamshidzadeh et al. [25] studied gas holdup conditions in mixer systems with non-Newtonian fluid. Khan et al. [26] used non-Newtonian Casson fluid to investigate y-shaped fin. Nguyen et al. [27] checked Boltzmann equation to simulate non-Newtonian flow using power law magnetic Reynolds number. Eberhard et al. [28] investigated non-Newtonian fluid in disordered porous structure with local viscosity effects. Studies on non-Newtonian fluids have made great improvements, especially in recent times. Since the working area of these fluids is quite wide. They vary for their characteristics and flow parameters. Studies can be experimental, theoretical or comparative. In this study, a numerical analysing method is used, and the results are compared.

\section{Materials and Methods}

A circular pipe having a diameter (D) of $0.1 \mathrm{~m}$ created. The length of pipe has 15D. A circular $2.5 \mathrm{~mm}$ thick obstacle is created 5D far away from the fluid inlet. The obstacle closes partially as a length of $40 \mathrm{~mm}$. Computational fluid dynamics is used in the analyses. The isometric view of geometry is given in Figure 1.

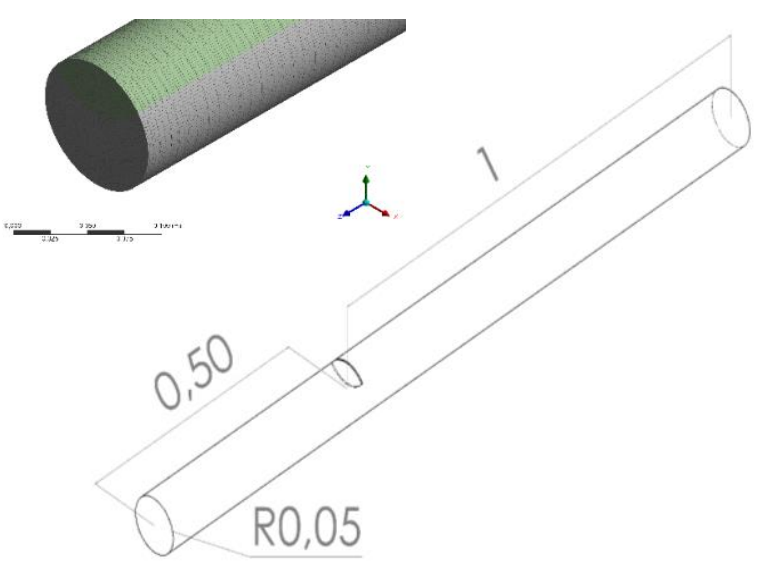

Figure 1. Isometric view of cylinder geometry (all dimensions are in $\mathrm{m}$ ).

A closer view of the CFD model is also illustrated. The prepared CFD model was checked with mesh independence test for maximum velocity in pipe for $n=2$ and $\mathrm{K}=0.1$ power law constants. The coarse and fine mesh variation was found at steady state approximately at 560,000 elements which total mesh quality was detected as 0.79 .

\subsection{Modelling and Boundary Conditions}

Non-Newtonian fluid flow is analysed by considering Power Law function. Viscosity is the critical parameter and can vary with the flow conditions. The basic form of the shear stress $(\tau)$ is given in $\mathrm{Eq}(.2 .1)$.

$$
\tau=K \times\left(\frac{d u}{d y}\right)^{n}
$$

$\mathrm{K}=$ flow consistency index

$\mathrm{n}=$ flow behaviour index

$\frac{d u}{d y}=$ shear rate

Effect of $\mathrm{n}$ and $\mathrm{K}$ is investigated with a constant density of $1000 \mathrm{~kg} / \mathrm{m}^{3}$. The inlet flow is selected as $0.01 \mathrm{~m} / \mathrm{s}$. Inside pipe surfaces are defined as wall. Laminar flow model is used with respect to non-Newtonian parameters and low inlet velocity.

\section{Results and Discussion}

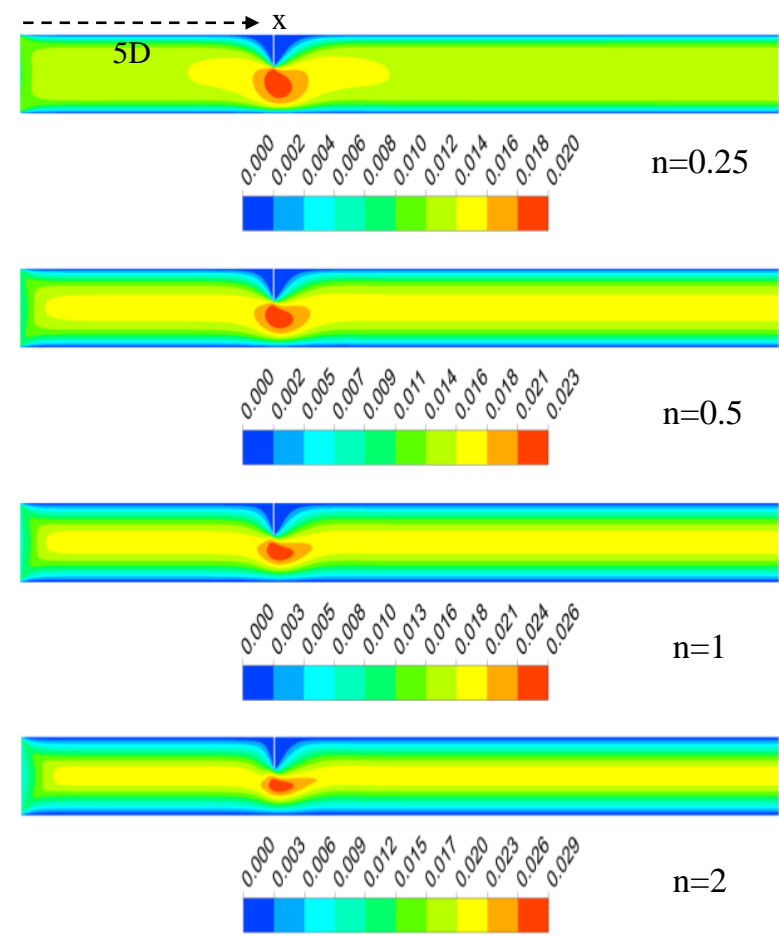

Figure 2. Velocity contours of various " $n$ " values with a constant value of $\mathrm{K}=0.1$

In Figure 2, the velocity contours are taken from a vertical section plane at the centre of pipe. The results show that the viscous flow dominantly interacts on the wall. As a result of the increased $n$ coefficient, the low or zero velocity profile interacting with the wall is more common. It was determined that there is a dead flow zone at the front and rear of the obstacle. The dead flow zone is greater behind the obstacle. The flow velocity increases in the transition section due to the narrowing of the cross section. With the increasing number of $n$, the flow tended to accelerate and showed a more 
parabolic high velocity structure in the pipe centre. This situation is also seen at the entrance to the pipe.

In Figure 3, velocity profile is given at 5D. There is no flow or velocity profile at the first $40 \mathrm{~mm}$ distance due to obstacle. That obstacle decreases the cross-section area of fluid pass and increases the velocity at the opened section. An asymmetrical velocity distribution profile is formed. Flow velocity profile is formed with a sharper and higher parabolic curve as a result of increasing $\mathrm{n}$ coefficient.

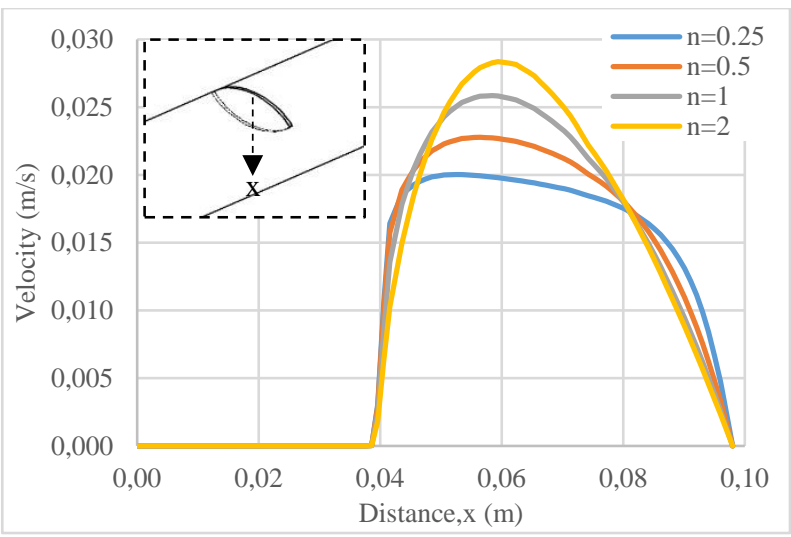

Figure 3. Velocity profiles of various " $n$ " values with a constant $\mathrm{K}$ value of 0.1 at $5 \mathrm{D}$.

In Figure 4, velocity profiles are given for $\mathrm{n}=0.25,0.5$, 1,2 . The flow has stabilized and shows a symmetrical distribution. This situation shows that the flow is not affected by the obstacle effect. As the value of $n$ increases in the non-Newtonian fluid, the maximum velocity increases.

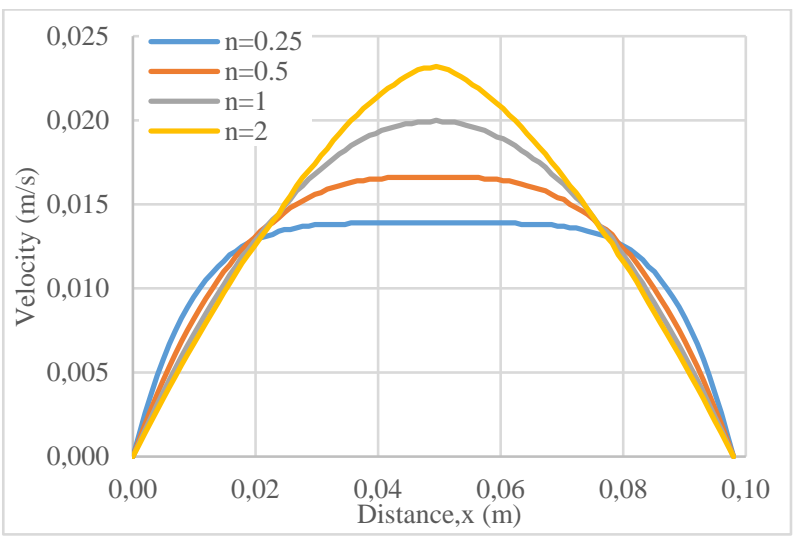

Figure 4. Velocity profiles of various " $n$ " values with a constant $\mathrm{K}$ value of 0.1 at $10 \mathrm{D}$.

When the results obtained along the whole channel in Figure 5 are examined, it is seen that the entire flow velocity increased as a result of the increasing $n$ coefficient. There is an instantaneous speed jump at the point where the obstacle flow is located. Considering the results of this instant speed jump, the value of $n=2$ with the highest velocity and the value of $n=1$ velocity reached the same value. The sudden increase in flow velocity has reached its former steady state one diameter ahead of the obstacle.

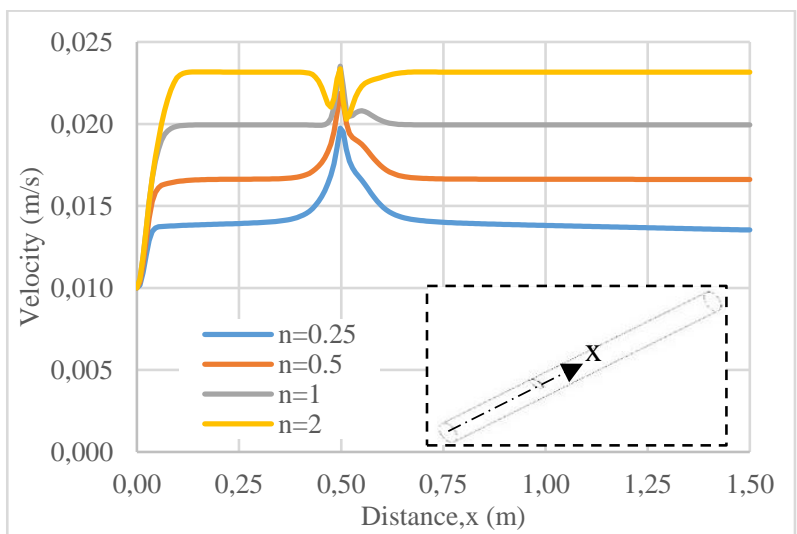

Figure 5. Velocity profiles of various " $n$ " values with a constant $\mathrm{K}$ value of 0.1 from inlet to outlet centre.

In Fig. 6 the pressure profile is shown for different $n$ coefficients. It was determined that the pressure decreased due to the increase in flow velocity after the obstacle. The lowest pressure profile is seen at $n=2$ where the velocity is the highest. There is about 2 times the difference between the highest and low pressures.

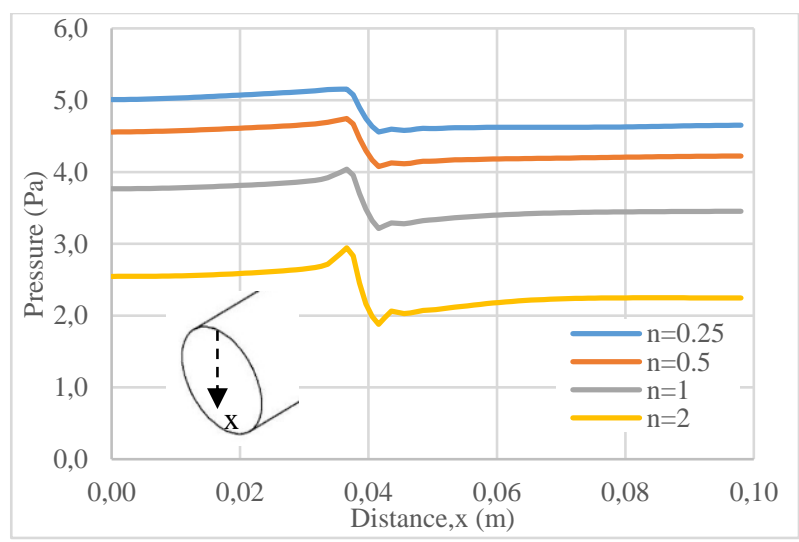

Figure 6. Pressure profiles of various "n" values with a constant $\mathrm{K}$ value of 0.1 at $5 \mathrm{D}$.

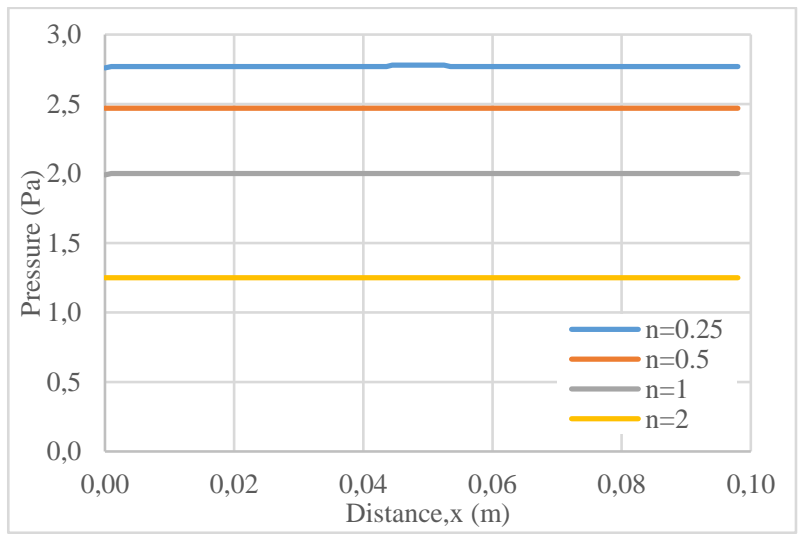

Figure 7. Pressure profiles of various "n" values with a constant $\mathrm{K}$ value of 0.1 at $10 \mathrm{D}$. 
Figure 8 shows the pressure graph for different $n$ coefficients along the length of the pipe. The graph starting with $3.5 \mathrm{~Pa}$ for the $\mathrm{n}=2$ value entered the pipe with a pressure 2 times higher for the value $n=0.25$. Pressure drop is observed instantaneously at the point where the obstacle is located. At this point the velocity increased.

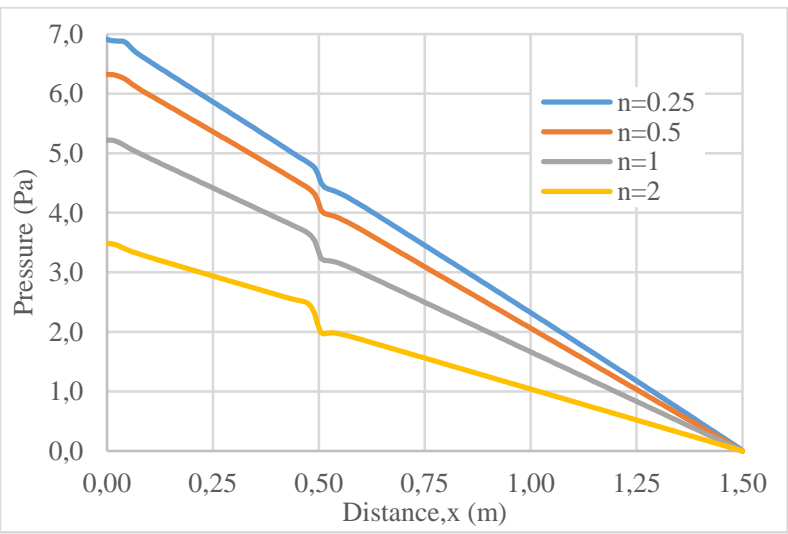

Figure. 8. Pressure profiles of various "n" values with a constant $\mathrm{K}$ value of 0.1 from inlet to outlet centre.

Figure 9 shows the effect of dynamic viscosity. The viscous effect behaved predominantly on the part of the wall with the obstacle. At $n=1$ and $n=2$, the wall interaction with dynamic viscous effect is not seen as dominant.

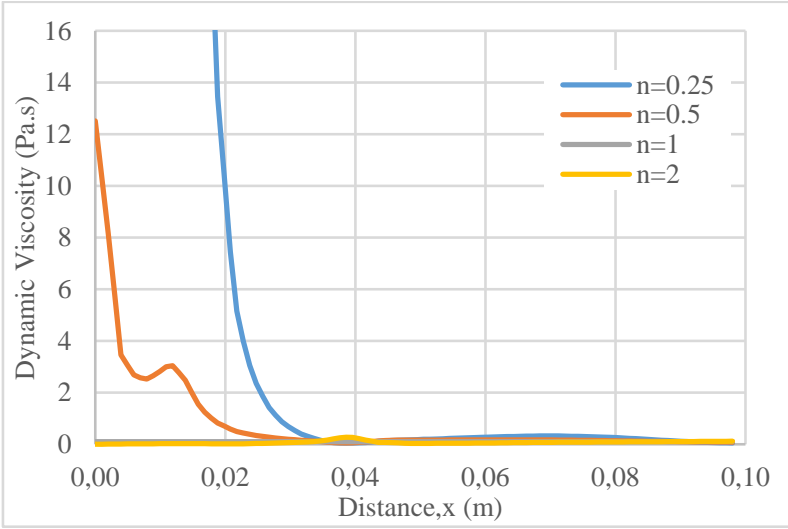

Figure 9. Dynamic viscosity profiles of various " $n$ " values with a constant $\mathrm{K}$ value of 0.1 at $5 \mathrm{D}$.

In Figure 10, the dynamic viscosity effect is shown at $10 \mathrm{D}$ for the condition where the flow develops. For $\mathrm{n}=$ 0.25 and $n=0.5$, viscosity is effective. However, the dynamic viscosity value has decreased 3 times in the fluid that travels the distance between 5D and 10D.

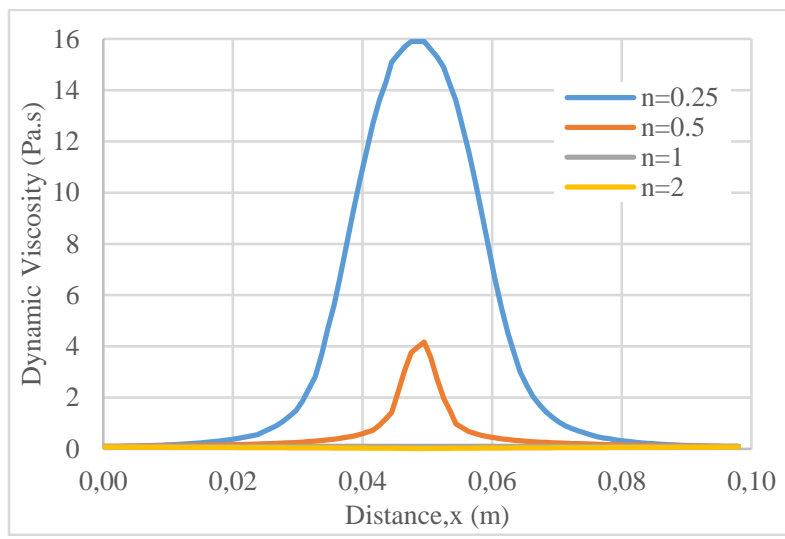

Figure 10. Dynamic viscosity profiles of various " $n$ " values with a constant $\mathrm{K}$ value of 0.1 at $10 \mathrm{D}$.

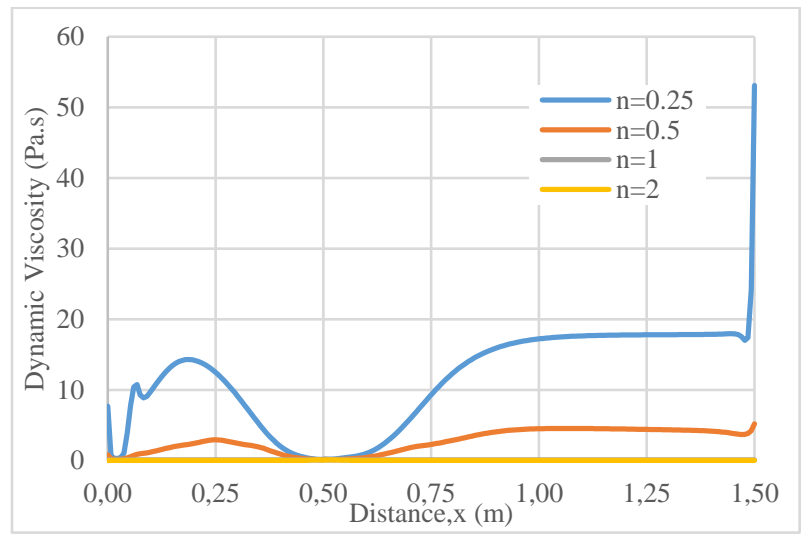

Figure 11. Dynamic viscosity profiles of various " $n$ " values with a constant $\mathrm{K}$ value of 0.1 from inlet to outlet centre.

Figure 11 shows the dynamic viscosity change along the pipe. The dynamic viscosity effect varies significantly within the pipe for coefficients $\mathrm{n}=0.25$ and 0.5 . Dynamic viscosity of $n=0.25$ behaves more precisely to intra-channel flow conditions.

The cell Reynolds number is shown in Fig. 12. As a result of the effect of increasing speed and low dynamic viscosity, the Reynolds number reached the highest value at $n=2$. At $n=0.25$, it instantly increases the Reynolds number at the corner of the obstacle. It is a factor that the viscosity of $n=0.25$ is higher than the other values of $n$ coefficients. 


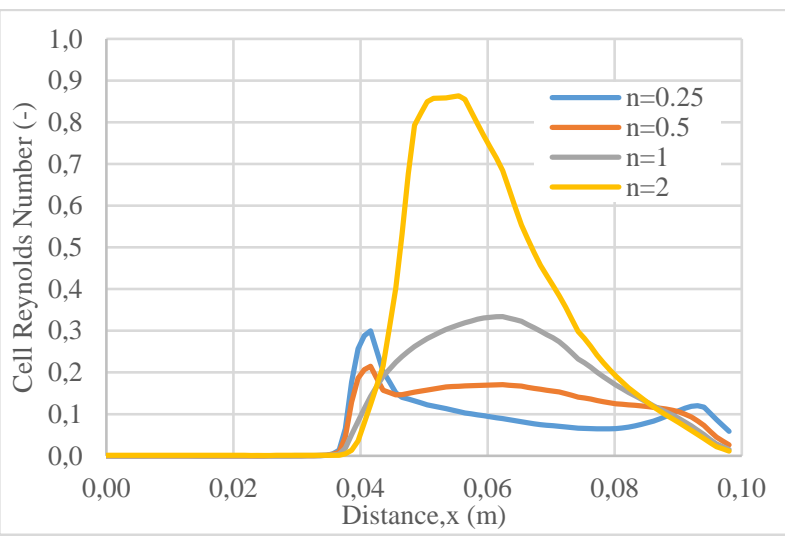

Figure 12. Cell Reynolds number profiles of various " $n$ " values with a constant $\mathrm{K}$ value of 0.1 at $5 \mathrm{D}$.

In Figure 13, in 10D, the Reynolds number increased at the centre when $n=1$ and $n=2$ coefficients are used. $B u$ However, in $n=0.25$ and $n=0.5$ results, $R e$ in the centre line decreased.

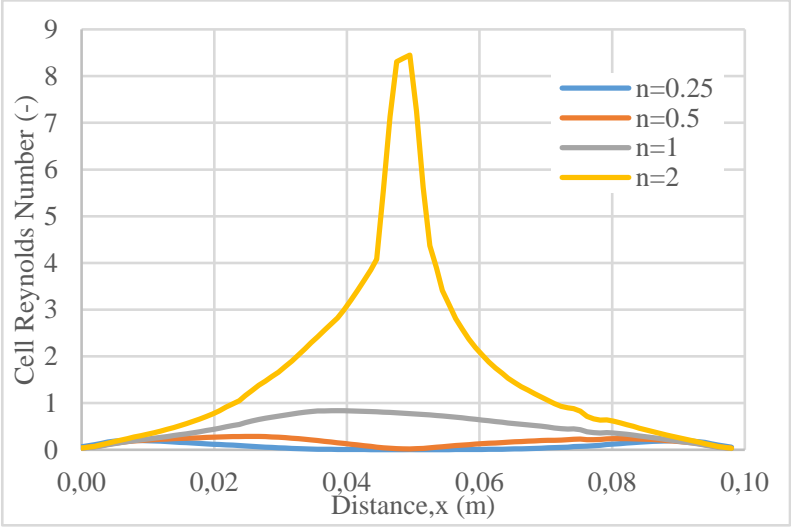

Figure 13. Cell Reynolds number profiles of various "n" values with a constant K value of 0.1 at $10 \mathrm{D}$.

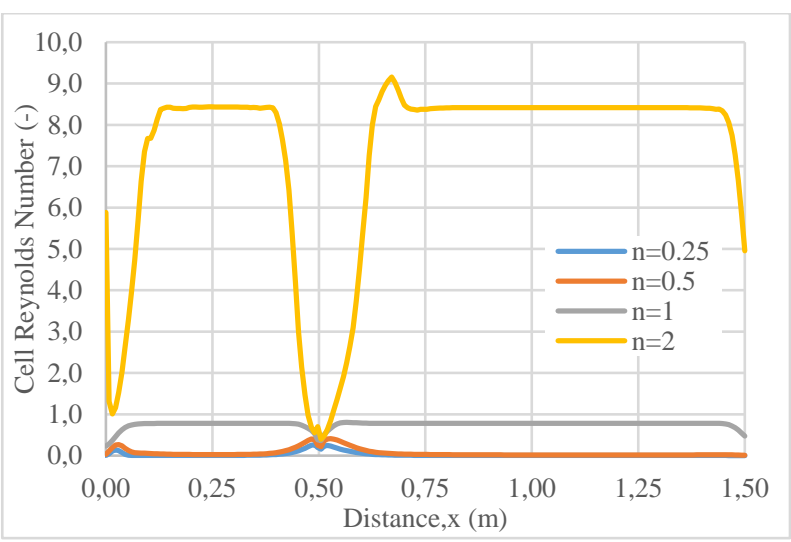

Figure 14. Cell Reynolds number profiles of various " $n$ " values with a constant $\mathrm{K}$ value of 0.1 from inlet to outlet centre.
In Fig. 14, it is seen that the Re number is very dominantly high at $n=0.25$. It was determined that the number of Re was low in the obstacle region. The Re number was more sensitive for $\mathrm{n}=2$.

Effect of $\mathrm{K}$ on pressure is given in Fig. 15. Whole various $\mathrm{K}$ distributions are similar, only its value changes. It was observed that the pressure increased rapidly with the $\mathrm{K}$ coefficient and it was determined that the flow needed higher pressure under these conditions. Velocity profile and magnitude is not affected and same as the first contour profile in Fig. 2.

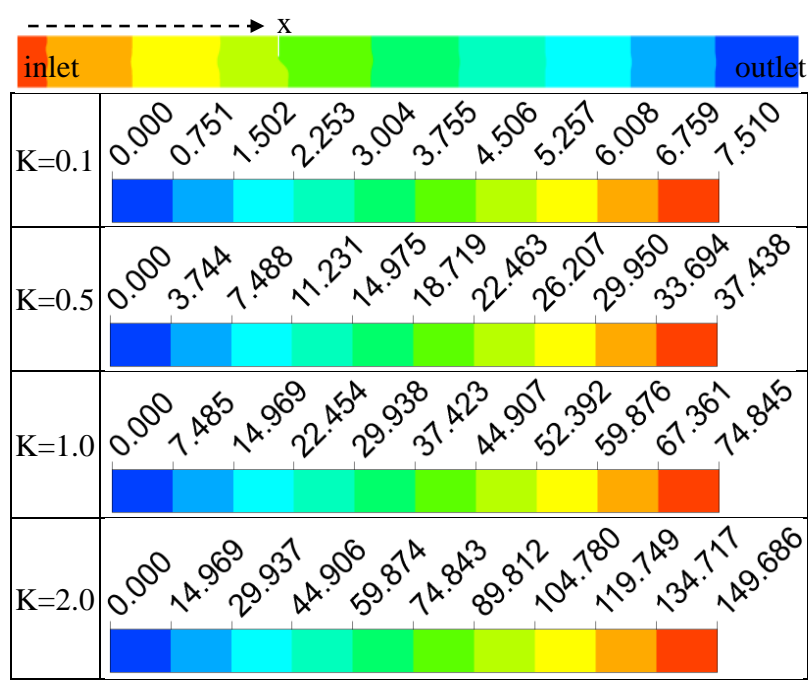

Figure 15. Pressure contours of various " $K$ " values with a constant value of $n=0.25$

In Fig. 16, the effect of $\mathrm{K}$ coefficient is shown in the obstacle region. Pressure values increased with the increase of $\mathrm{K}$. The corner of the barrier has a reduction effect.

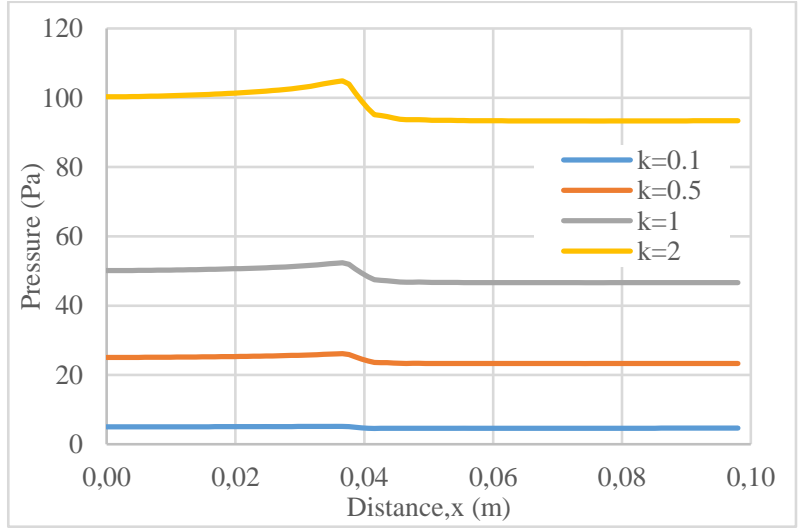

Figure 16. Pressure profiles of various " $\mathrm{K}$ " values with a constant $n$ value of 0.25 at $5 \mathrm{D}$. 


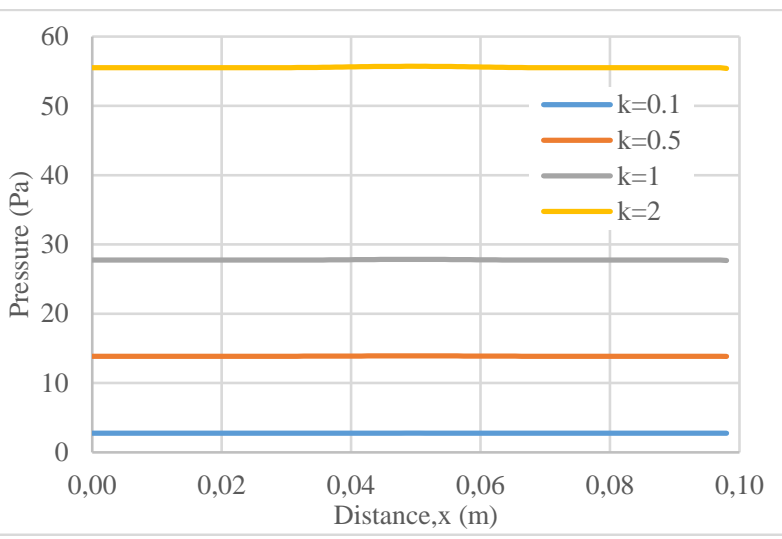

Figure 17. Pressure profiles of various " $K$ " values with a constant $n$ value of 0.25 at $10 \mathrm{D}$.

Figure 17 shows the pressure values at 10D distance. The pressure, which is $56 \mathrm{~Pa}$ at $\mathrm{K}=2$, decreases as a result of the increase in the $\mathrm{K}$ value.

The results of Fig. 18 show a high-pressure requirement for $K=2$. The pressure of the flow decreases with the decrease of the $\mathrm{K}$ value.

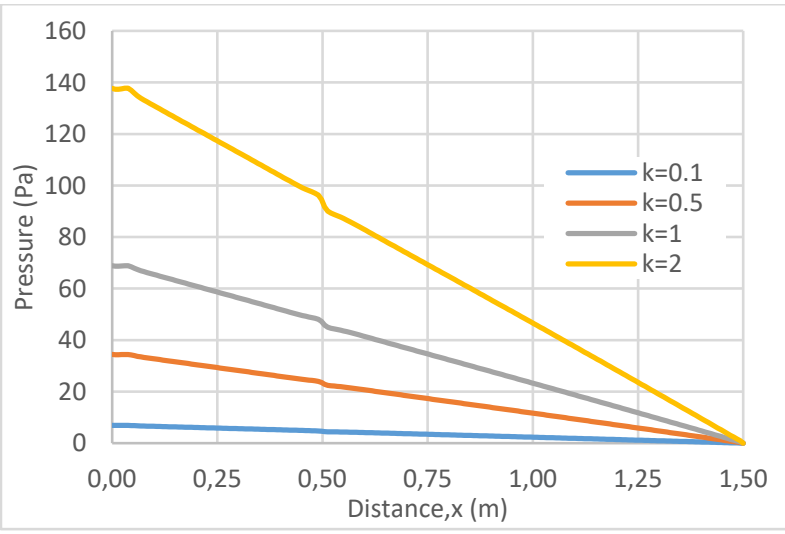

Figure 18. Pressure profiles of various " $K$ " values with a constant $n$ value of 0.25 from inlet to outlet centre.

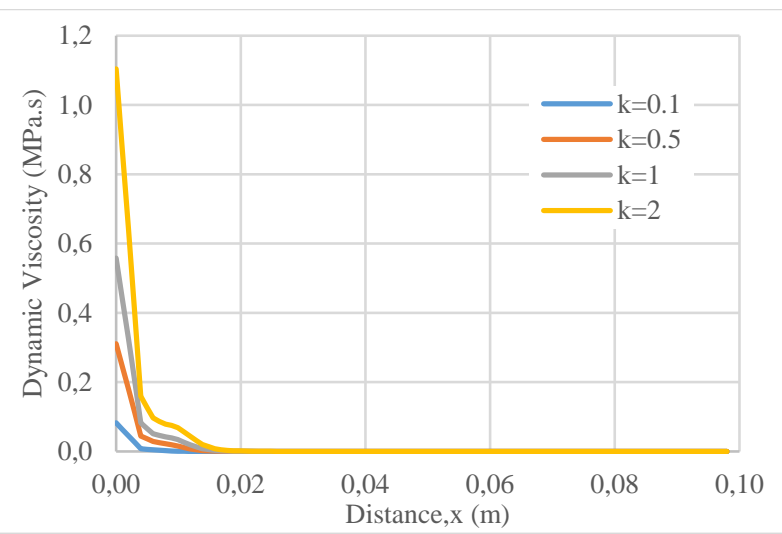

Figure 19. Dynamic viscosity profiles of various " $K$ " values with a constant $n$ value of 0.25 at $5 \mathrm{D}$.
The effect of $\mathrm{K}$ coefficient on dynamic viscosity is shown in the obstacle line in Fig. 19. An instantaneous great value was observed at the obstacle-wall corner where there was dead flow. Dynamic viscosity showed an unstable state.

Figure 20 shows the effect of dynamic viscosity in the $10 \mathrm{D}$ region. More stable results were obtained in this region where the barrier effect is not dominant. While the dynamic viscosity was above $300 \mathrm{~Pa}$.s for the $\mathrm{K}=2$ value, it decreased to $20 \mathrm{~Pa}$.s for $\mathrm{K}=0.1$.

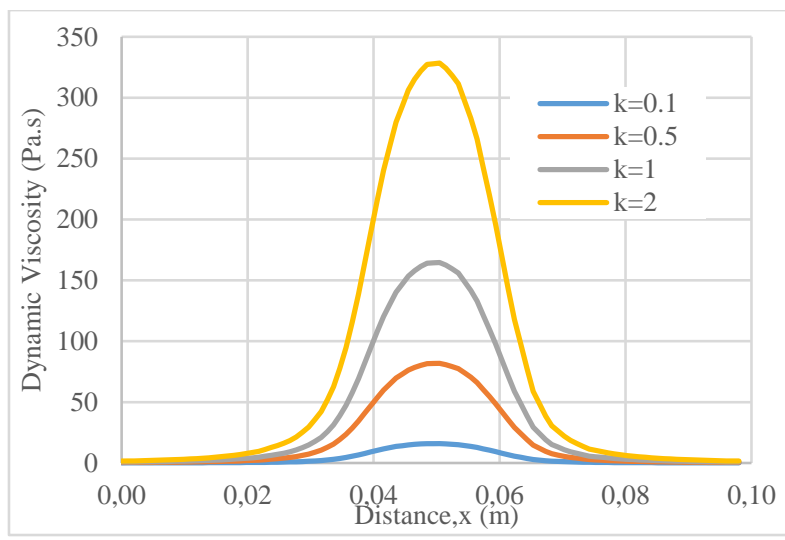

Figure 20. Dynamic viscosity profiles of various " $\mathrm{K}$ " values with a constant $n$ value of 0.25 at $10 \mathrm{D}$.

Figure 21 shows the dynamic viscosity effect along the entire pipeline. The dynamic viscosity was reduced in all $\mathrm{K}$ coefficient results due to the obstacle. The highest results were obtained at $\mathrm{K}=2$ and the lowest results at $\mathrm{K}=0.1$.

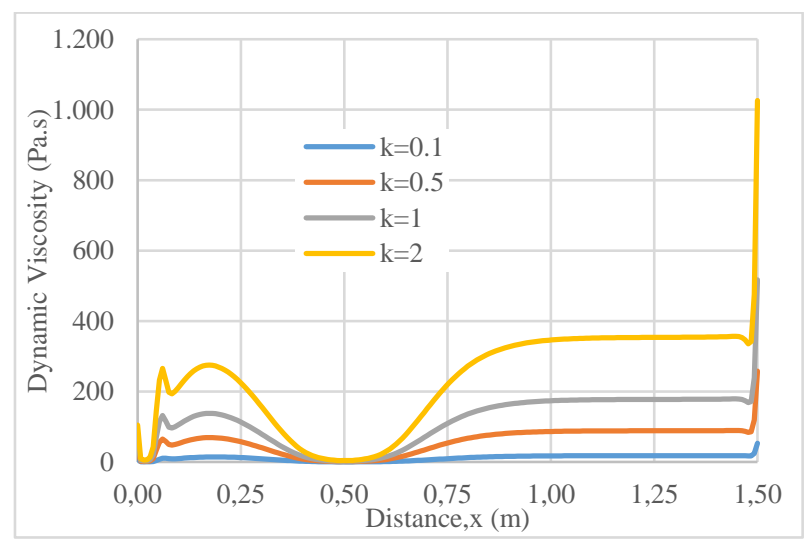

Figure 21. Dynamic viscosity profiles of various " $K$ " values with a constant $n$ value of 0.25 from inlet to outlet centre.

Re number results for different $\mathrm{K}$ coefficient are shown in Fig. 22. The highest results were obtained with a value of $\mathrm{K}=0.1$. The lowest result was obtained at $\mathrm{K}=$ 2. 


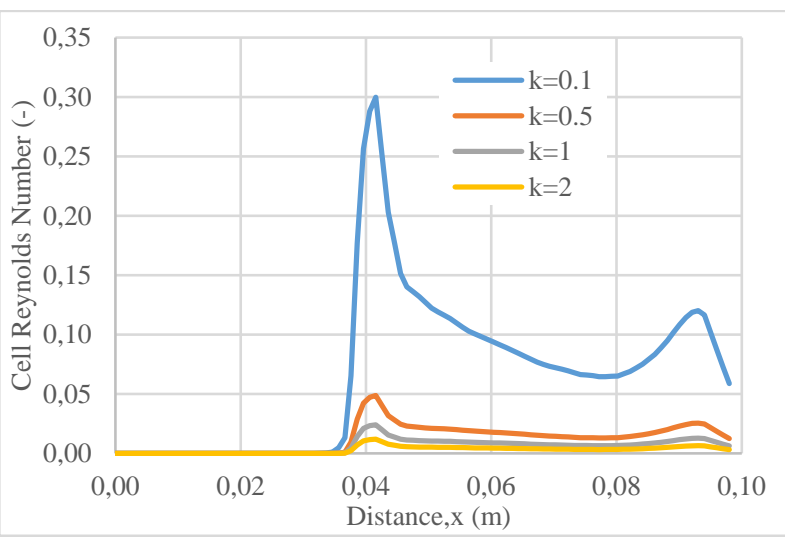

Figure 22. Cell Reynolds number profiles of various "K" values with a constant $n$ value of 0.25 at $5 \mathrm{D}$.

Figure 23 shows the results of the Re number in the region of $10 \mathrm{D}$. The increasing $\mathrm{K}$ number decreased the Re number. Results showed a wavy profile. The lowest values were observed in the centre of the pipe. Moderate results are seen near the pipe surface. The highest values were obtained between the wall and the pipe centre.

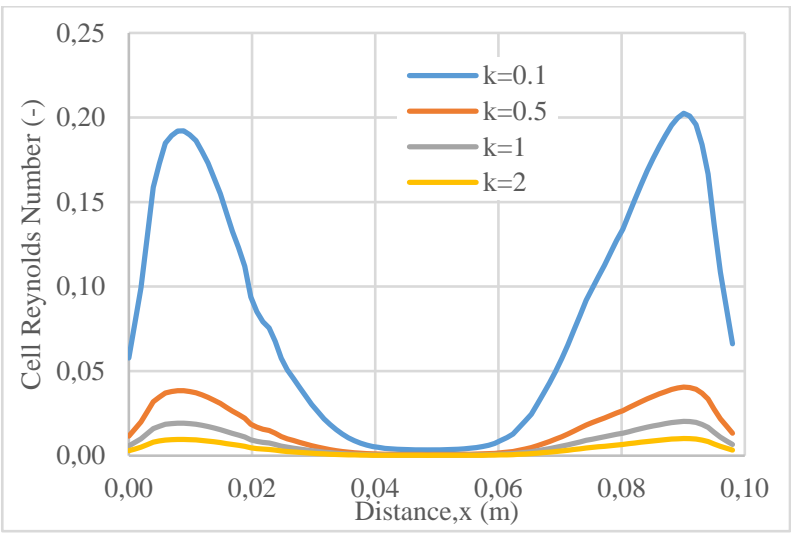

Figure 23. Cell Reynolds number profiles of various "K" values with a constant $n$ value of 0.25 at $10 \mathrm{D}$.

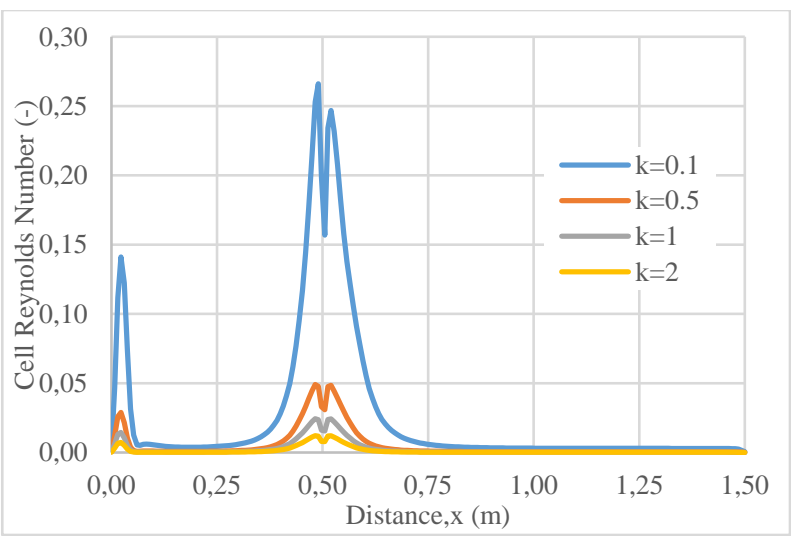

Figure 24. Cell Reynolds number profiles of various " $\mathrm{K}$ " values with a constant $\mathrm{n}$ value of 0.25 from inlet to outlet centre.
Figure 24 shows the Re number along the entire pipe direction. With the decrease in the $\mathrm{K}$ number, there was an increase in the $\mathrm{Re}$ number. The $\mathrm{Re}$ number is determined as the highest in the front and rear of the obstacle. Some decrease in Re number was observed during the flow passing the obstacle.

\section{Conclusion}

Non-Newtonian flow analysis was carried out in a pipe with obstructed flow. The effect of different $\mathrm{n}$ and $\mathrm{K}$ coefficients was examined in the study using numerical analysis method. Results are shown in contours and graphics.

\section{In summary;}

While the number of $\mathrm{K}$ was constant, increasing the number of $\mathrm{n}$ caused the flow velocity to increase.

As a result of the velocity increase, a more parabolic flow velocity profile was formed.

Flow velocity of $0.01 \mathrm{~m} / \mathrm{s}$ increased up to $0.023 \mathrm{~m} / \mathrm{s}$ when $\mathrm{n}=0.25$.

At the moment of passing the obstacle, the velocity in front and back of the obstacle instantly decreased at $\mathrm{n}=$ 2 , and the other $\mathrm{n}$ values did not decrease.

As a result of the increasing $\mathrm{n}$ value, a lower pressure profile has occurred in the pipe. This shows that flow can be achieved with a lower pressure.

Dynamic viscosity effect was more dominant at $\mathrm{n}=0.25$ and $n=0.5$ coefficients. However, a lower Re number was obtained.

Different K coefficients were examined for the $\mathrm{n}=0.25$ coefficient, where the viscous flow exhibits a more sensitive state.

With the increase of the $\mathrm{K}$ coefficient, higher-pressure values were obtained in the solutions. It appears that a higher pressure is required for the pipe flow.

When $\mathrm{K}=2$, dynamic viscosity has the highest value. However, Re number was obtained as the lowest.

While the Re number reached the highest value at the front and rear of the obstacle, a momentary decrease was observed in the area where the flow passed the obstacle.

Throughout a diameter in front and behind the obstacle, this effect continues predominantly.

\section{Author's Contributions}

Mustafa Murat Yavuz: Drafted the manuscript, performed the numerical model and result analysis.

Pınar Sarı Çavdar: Performed result interpretation and wrote manuscript preparation. 


\section{Ethics}

There are no ethical issues after the publication of this manuscript.

\section{References}

1. Bird, RB, Stewart, WE., Lightfoot, EM. 1960. Transport phenomena, John Wiley, New York.

2. Hansen, AG., Na, TY. 1968. Similarity solution of laminar, Incompressible boundary layer equations of non-Newtonian fluid, ASME Journal of Basic Engg. 67: 71-74.

3. Kapur JN, Bhatt BS, Sacheti NC, 1982. Non-Newtonian fluid flows, Pragati Prakashan, Meerut, India.

4. Lee SY, Ames WF,1996. Similar solutions for non-Newtonian fluids, AIChE J. 12: 700-708.

5. Timol MG, Patel M, 2004. On the class of similarity solutions for three dimensional boundary layer flows of non-Newtonian fluids, J. of Veer Narmad South Gujarat University. II-B, 103-109.

6. Wells CS, 1964. Unsteady boundary layer flow of a non-Newtonian fluid on a flat plate, AIAA Journal. 2(5) :951-952.

7. Bizzell GD, Slattery JC,1962. Non-Newtonian boundary-layer flow, Chemical Engineering Science. 17(10):777-782.

8. Djukic DjS,1973. On the use of Crocco's equation for the flow of power-law fluids in a transverse magnetic field, AIChE Journal. 19: 1159-1163.

9. Djukic DjS, 1974. Hiemenz magnetic flow of power-law fluids, Journal of Applied Mechanics, Transaction of the ASME, 822-823.

10. Na TY, Hansen A, 1967. Radial flow of viscous non-newtonian fluids between disks, Int. J. Non-Linear Mech. 2: 261-273.

11. Patel M, Timol MG, 2011. Orthogonal stagnation point flow of a power-law fluid toward a stretching surface, International Journal of Applied Mechanics and Mathematics (IJAMM). 7(3): 31-37.

12. Patel M, Patel R, Timol MG, 2012. Group invariance for nonlinear pde's: 3-d mhd stagnation point flow of non-newtonian powerlaw fluids, International Journal of Mathematics and Scientific Computing (IJMSC). 2(2):72-80.

13. Patel M, Patel R, Timol MG, 2014. Numerical treatment of MHD Power-law fluid flow using the method of satisfaction of asymptotic boundary conditions (MSABC), International Journal of Applied Mechanics and Mathematics. 10(8):61-77.

14. Gupta RC, On developing laminar non-Newtonian flow in pipes and channels, Nonlinear Analysis: Real World Applications. 2: 171193.

15. Alexandrou AN, McGilvreay TM, Burgos G,2001. Steady Herschel-Bulkley fluid flow in three-dimensional expansions, J. NonNewtonian Fluid Mech. 100: 77-96.

16. Cebeci T, Clauss JM, Dyer J, 1969. On the solution of boundarylayer equations for a non-Newtonian power-law fluid, Chemical Engineering Science. 24: 1031-1034.

17. Acrivos A, Shah MJ, Petersen EE, 1965. On the solution of the two-dimensional boundary-layer flow equations for a non-Newtonian power law fluid, Chemical Engineering Science. 20(2): 101-105.

18. Hornbeck RW,1964. Laminar flow in the entrance region of a pipe. Applied Scientific Research, Section A. 13:224-232.
19. Yapıc1 H, Albayrak B, 2004. Numerical solutions of conjugate heat transfer and thermal stresses in a circular pipe externally heated with non-uniform heat flux, Energy Conversion and Management. 45(6): 927-937.

20. Yildırım N, Buchlin J, Benocci C,2017. Simulation of surface instability at the interface of two fluids. Celal Bayar University Journal of Science. 13(2): 365-377.

21. Kırmızıgöl SF, Özaydın O, Acarer S, Armakan E, 2020. Fluid flow and heat transfer simulations of the cooling system in low pressure die casting, Celal Bayar University Journal of Science. 16(2):161-168.

22. Sorgun M, Haşıloğlu DG, 2016. Effect of pipe roughness on pressure losses of newtonian fluids in concentric annulus, Celal Bayar University Journal of Science. 12(3): 413-417.

23. Batool S, Nawaz M, 2020. Investigation of thermal enhancement in non-Newtonian fluid with hybrid microstructures in an enclosure, International Communications in Heat and Mass Transfer. 117:104777.

24. Mehryan SAM, Heidarshenas MH, Hajjar A, Ghalambaz M, 2020. Numerical study of melting-process of a non-Newtonian fluid inside a metal foam, Alexandria Engineering Journal. 59: 191-207

25. Jamshidzadeh M, Ein-Mozaffari F, Lohi A, 2020. Local and overall gas holdup in an aerated coaxial mixing system containing a non-Newtonian fluid, Transport Phenomena and Fluid Mechanics. 66: 1-16.

26. Khan ZH, Khan WA, Hamid M, 2021. Non-Newtonian fluid flow around a $\mathrm{Y}$-shaped fin embedded in a square cavity, Journal of Thermal Analysis and Calorimetry. 143: 573-585.

27. Nguyen Q, Ghahderijani MJ, Bahrami M, Ahangar EK, D'Orazio A, Bach Q, Karimipour A, 2020. Develop Boltzmann equation to simulate non-Newtonian magneto-hydrodynamic nanofluid flow using power law magnetic Reynolds number, Math Meth Appl Sci., 1-16.

28. Eberhard U, Seybold HJ, Secchi E, Jiménez-Martínez J, Rühs PA, Ofner A, Andrade Jr JS, Holzner M, 2020. Mapping the local viscosity of non-Newtonian fluids flowing through disordered porous structures, Scientific Reports. 10, 11733. 